\title{
Trans-diaphragmatic chest surgery: Bringing owls to Athens?
}

\author{
Ze-Rui Zhao, MD, ${ }^{\mathrm{a}}$ Zheng Li, PhD, ${ }^{\mathrm{b}}$ and Calvin S. H. Ng, MD, FRCS ${ }^{\mathrm{a}}$
}

\footnotetext{
From the a Division of Cardiothoracic Surgery, Department of Surgery, The Chinese University of Hong Kong, Prince of Wales Hospital, Hong Kong SAR, China; and ${ }^{\mathrm{b}}$ Department of Surgery, Chow Yuk Ho Technology Centre for Innovative Medicine, The Chinese University of Hong Kong, Hong Kong, China.

Disclosures: Authors have nothing to disclose with regard to commercial support.

Received for publication Nov 10, 2017; accepted for publication Nov 15, 2017; available ahead of print Jan 11, 2018

Address for reprints: Calvin S. H. Ng, MD, FRCS, Division of Cardiothoracic Surgery, The Chinese University of Hong Kong, Prince of Wales Hospital, Shatin, N.T., Hong Kong SAR, China (E-mail: calvinng@surgery.cuhk. edu.hk).

J Thorac Cardiovasc Surg 2018;155:1300-1

$0022-5223 / \$ 36.00$

Copyright (c) 2017 by The American Association for Thoracic Surgery

https://doi.org/10.1016/j.jtcvs.2017.11.063
}

It has long been the ethos of minimally invasive thoracic surgeons to pursue ways to reduce surgical access trauma. Minimizing the number of incisions, namely, uniportal video-assisted thoracic surgery (VATS), may be associated with potentially less injury to intercostal nerves ${ }^{1}$ and is gaining popularity worldwide. The idea of reducing intercostal nerve injury has to be taken a step further by altogether avoiding incisions at intercostal spaces. Hand-assisted sternocostal triangle access ${ }^{2}$ VATS provided the start to the era of nontransthoracic approach to thoracic surgery. Subsequently, other alternate access approaches, including uniportal subxiphoid VATS for thymectomy and anatomic lung resections, were reported. ${ }^{3,4}$

In this issue, Santiago-Andrade and colleagues ${ }^{5}$ describe their early experience of laparoscopic trans-diaphragmatic (LTD) thoracic surgery. The novel technique has similarity and may be regarded as the multi-port form of the approaches described. However, the proposed method requires intraperitoneal endoincisions of the diaphragm and continuous U-stitch traction, which is not needed for subxiphoid route. They found less postoperative opioid use compared with VATS; however, the lack of pain score measurement for the groups in a small retrospective study makes interpretation difficult. In terms of limitations, even advocates of the subxiphoid approach have expressed difficulties with lower lobe resections and N2 lymph node dissection, particularly on the left side. Of note, lower lobe procedures consisted most of the anatomical resection in the current report on LTD surgery, although the data on lymph nodes harvested are not well reported, with some cases receiving trans-cervical extended mediastinal lymphadenectomy. The more prolonged path the LTD endoscopic instruments have to advance may partly explain the favor for lower lobe resections.

A number of other issues need to be evaluated before the LTD approach can be considered for adoption. First, with multiple diaphragmatic incisions, the possibility and consequence of a tumor being introduced

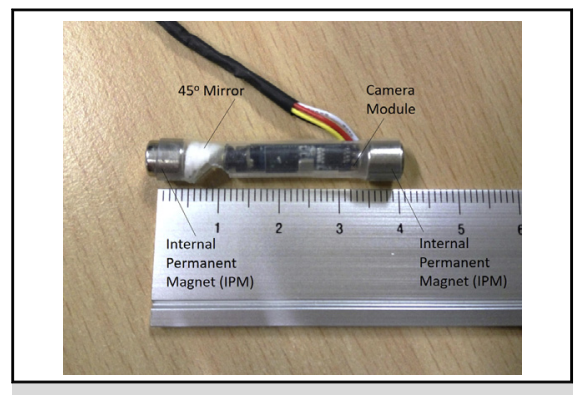

Tiny, magnetic, anchoring, actuated endoscope allows it to be placed within the chest cavity.

\section{Central Message}

The LTD route is a novel approach to chest surgery and may enhance the armamentarium of minimally invasive surgeons. Its limitations and outcomes require further assessment.

See Article page 1294.

into another body cavity for oncologic surgery are present. Furthermore, postoperative ileus, formation of intra-abdominal adhesions, and the consequence of multiple diaphragmatic incisions on postoperative pulmonary function, pain, and morbidity will all need to be carefully studied. Long-term influence on the diaphragm is also a concern, just as the authors suggested avoiding LTD in young patients who require heavy lifting.

From a technical standpoint, the LTD approach in the future will benefit from fewer incisions on the abdomen and diaphragm. More advanced camera systems, such

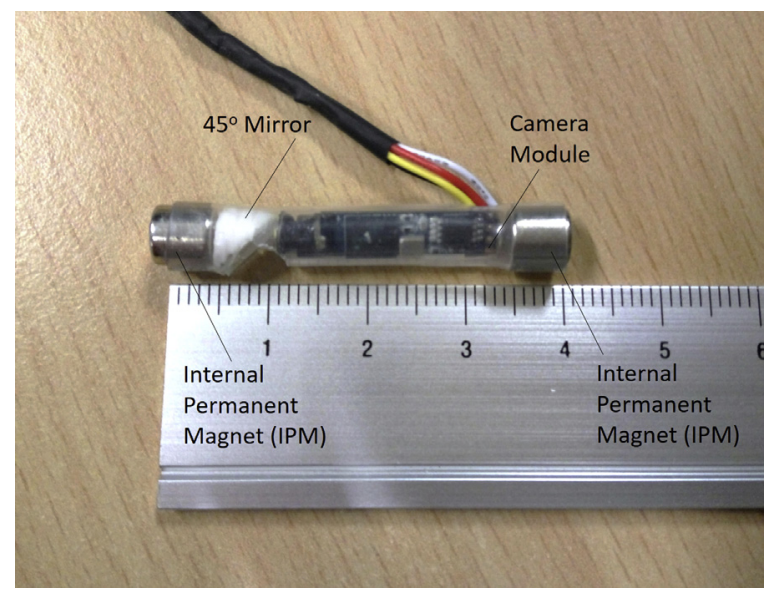

FIGURE 1. Tiny, magnetic, anchoring, actuated endoscope allows it to be placed within the chest cavity. 
as magnetic anchoring and actuated endoscopes ${ }^{6-8}$ (Figure 1), allow omission of the rigid-shaft endoscope and its port. In addition, rapid development of single-incision robots platforms and natural orifice transluminal endoscopic surgery technology may further reduce the incisions needed. ${ }^{6,8,9}$ Another problem inherent in all "remote" access surgery is the lack of digital palpation for lung lesion localization. Emerging localizing techniques by hookwire placement or dye marking in the hybrid operating room ${ }^{10}$ could provide a reliable 1-stop solution. Caution needs to be exercised for LTD surgery until more clinical data emerge. Although Leonardo da Vinci once said "Simplicity is the ultimate sophistication," we should not easily dismiss innovative surgical approaches that often drive technologic and technical advances in surgery. ${ }^{11-13}$

\section{References}

1. Ng CS, Wong RH, Lau RW, Yim AP. Minimizing chest wall trauma in single port video-assisted thoracic surgery. J Thorac Cardiovasc Surg. 2014;147: 1095-6.

2. Long H, Zheng Y, Situ D, Ma G, Lin Z, Wang J. Hand-assisted thoracoscopic surgery for bilateral lung metastasectomy through sternocostal triangle access. Ann Thorac Surg. 2011;91:852-8.
3. Ng CSH. Uniportal video assisted thoracic surgery - a look into the future. Eur J Cardiothorac Surg. 2016;48:11-2.

4. Liu CC, Wang BY, Shih CS, Liu YH. Subxiphoid single-incision thoracoscopic left upper lobectomy. J Thorac Cardiovasc Surg. 2014;148:3250-1.

5. Santiago-Andrade R, Diaz-Gutierrez I, Hutchins J, Kaizer A, Small J, Rao M. Laparoscopic trans-diaphragmatic chest surgery: early experience. J Thorac Cardiovasc Surg. 2018;155:1294-9.

6. Ng CSH, Rocco G, Wong RHL, Lau RWH, Yu SCH, Yim APC. Uniportal and single incision video assisted thoracic surgery- the state of the art. Interact Cardiovasc Thorac Surg. 2014;19:661-6.

7. Gonzalez-Rivas D, Yang Y, Ng C. Advances in uniportal video-assisted thoracoscopic surgery: pushing the envelope. Thorac Surg Clin. 2016;26:187-201.

8. Ng CSH, He JX, Rocco G. Innovations and technologies in thoracic surgery. Eur J Cardiothorac Surg. 2017;52:203-5.

9. $\mathrm{Li} \mathrm{Z}, \mathrm{Ng} \mathrm{CSH}$. Future of uniportal video-assisted thoracoscopic surgery - emerging technology. Ann Cardiothorac Surg. 2016;5:127-32.

10. Zhao ZR, Lau RWH, Ng CSH. Hybrid theater and uniportal video-assisted thoracic surgery: the perfect match for lung nodule localization. Thorac Surg Clin. 2017:27:347-55.

11. 2000 July 31, The New Yorker, (Multipage advertising insert from Campari; title: Inizio: Stimulating the Appetite for Food Life and Excitement; sub-section: Editor's Note; guest editor: Pietro Logaldo), Quote Page 40c, Published by Condé Nast, New York. (Electronic New Yorker Archive of Page Scans).

12. 2000 September 12, Investor's Business Daily, Wisdom To Live By, Quote Page 4, Los Angeles, California. (NewsBank Access World News).

13. 2002 October 5, The Times, Article title: Wizards of Oz rip up the rules - The Times Cook, Article author: Jill Dupleix, Quote Page: Weekend 4, London, England. (Access World News). 